\title{
Autosomal recessive hyperinsulinism due to SUR1 deficiency
}

INSERM

\section{Source}

INSERM. (1999). Orphanet: an online rare disease and orphan drug data base. Autosomal recessive hyperinsulinism due to SUR1 deficiency. ORPHA:79643

A rare, congenital, isolated hyperinsulinism disorder characterized by neonatal presentation of severe refractory hypoglycemia in the first two days of life, with limited response to medical management, sometimes requiring pancreatic resection. Newborns are often large for gestational age with mild to moderate hepatomegaly and diffuse form of hyperinsulinism due to SUR1 deficiency. Persistent hypoglycemia, hyperglycemia and type1 diabetes mellitus may develop later in life. Life-threatening hypoglycemic coma or status epilepticus have also been associated. 